\title{
Link between aging and the nucleolus
}

\author{
Leonard Guarente ${ }^{1}$ \\ Department of Biology, M assachusetts Institute of Technology, Cambridge, M assachusetts 02139 USA
}

Our ancient ancesters recognized events of nature, like the sporadic appearance of comets and lightning, the periodic display of stars, planets, and the moon, and biological processes like birth, development, and aging. The rapid progress of science has formulated a firm basis for understanding many of these phenomena, but aging has remained a conspi cuous exception. Recently, however, a concerted effort has been made to get at the scientific basis of what cellular and molecular events might cause aging. This perspective will begin with an introduction into new approaches being used to study aging. The main body will focus on two independent studies in a model system that both point to the cell as a probable unit of aging and the nucleolus as a key player in the aging process. Finally, these recent findings will be placed into a context of human aging, which considers a possible interplay between tel omeres and the nucleolus, as well as the rel ationship between di viding and nondividing (postmitotic) cells.

\section{Background}

How do we define aging? There are two reliable measures of aging, the first statistical, and the second descriptive (but amenable to quantitation). In the 1820s, a statistician, Gompertz (1825), noted that human mortality rates increase exponential ly with age, giving rise to a survival curve depicted in Figure 1A. These kinetics are indicative of a progressive degenerative process and are observed in many organisms, including mammals, flies, worms, plants, and yeast mother cells. These kinetics contrast with stochastic death, for example, by predation, which would give rise to a curve similar to the decay of a radioisotope (Fig. 1B). The second definition of aging is changes in phenotype that occur in all of the individuals over time. In humans it is relatively clear whether someone is young, middle aged, or elderly by their appearance. The above definitions apply to organisms that age, and they both will be used in this paper.

How can one study aging to identify root causes? A useful analogy here is cancer. Twenty years ago, many differences between cancer cells and normal cells had been cataloged, but a fundamental cause of cancer remained elusive. M olecular causes of cancer were brought to light by the identification of oncogenic mutations in

1E-MAIL leng@mit.edu; FAX (617) 253-8699. normal cellular genes that caused a loss of growth control. Likewise in aging research, there has recently been a concerted effort to identify genes that alter the rate of aging, when mutated.

Studies of the genetics of aging are possible in model systems. In Caenorhabditis elegans, mutations have been identified that al low the animal to live longer than wild type. These mutations fall into two categories. The first is mutations that activate the Dauer larvae pathway (Kenyon et al. 1993). Typically, worms will enter a dormant state termed Dauer when they are nutritionally limited at a time early in development. They can exist in this state for months, much longer than their typical 2 -week life span. Mutations in daf-2 or age-1/daf-23 (Friedman and Johnson 1988; M orris et al. 1996) can turn on the Dauer pathway at a time in development of the experimenter's choice. By activating the Dauer pathway in adults, worms can be made to live twice as long as wild type. The sequence of daf- 2 and daf-23 reveal an insulin-like receptor (Ki mura et al . 1997) and a phosphatidylinositol-3-OH (PI3) kinase (Morris et al. 1996), respectively, suggesting that the Dauer pathway may be determined by an intercellular signaling pathway that slows metabolism in Dauer animals. It is thus possible that the activation of this pathway in adults also slows metabolism, giving rise to a long life span, although metabolic effects are not readily observable in these daf adults.

Another class of $\mathrm{C}$. el egans mutants affects genes termed clk (Wong et al. 1995). clk-1 mutations slow down development and rhythmic movements in adults, and these mutants live longer (Lakowski and Hekimi 1996). The sequence of clk-1 (Ewbank et al . 1997) is similar to a yeast gene, CAT5 (Proft et al . 1995), that activates oxidative metabolism, again suggesting that the clk-1 mutant owes its longevity to a slowing in metabolism. It is of interest that all of the cells of the adult worm are postmitotic; thus this system may be an excellent model for aging in mammalian organs consisting of nondi viding cells (e.g., brain and heart).

A nother model system is the budding yeast Saccharomyces cerevisiae. The asymmetric cell division in budding yeast gives rise to a large mother cell and a small daughter cell arising from the bud (Fig. 2). At least some of the components of the daughter, such as the cell surface, are newly synthesized during the budding process. Thus, the mother is a repository for many cellular constituents that get older with each budding. By following 
A AGING

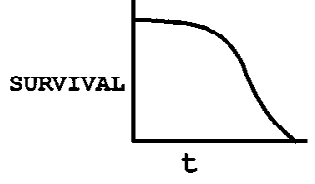

B STOCHASTIC

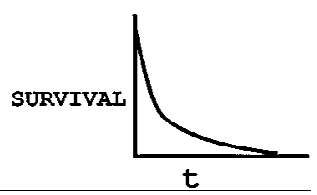

Figure 1. Kinetics of aging. (A) The survival curve of a cohort of individuals over time. The precipitous decline is attributable to the exponential increase in mortality rates over time, as first described by Gompertz (1825). (B) The curve for an organism that dies stochastically.

the mother cell through multiple rounds of division microscopically, it was demonstrated that they divided a relativel y fixed number of times (M ortimer and Johnston 1959) and that they displayed Gompertz kinetics of death (Pohley 1987). Y east mother cel Is may therefore be assigned an average and maximum life span, which varies from strain to strain. Furthermore, mother cells adopt characteristic phenotypes with age, such as an increase in cell size and a slowing of the cell cycle. Thus, mother cells meet both the statistical and phenotypic definitions of aging.

Using this system, Jazwinski and colleagues have identified genes that are preferentially expressed in young or old cells, and some of these, such as LAG1 (D'M ello et al. 1994), are important determinants of life span, although their function is not yet known. The yeast RAS genes are another determinant of life span, suggesting that a link between metabolism and life span is al so present in yeast (Sun et al. 1994).

In addition to model systems, nature may have provided another genetic clue about aging. Certain human di seases cause a phenocopy of premature aging in a variety of organ systems. These include Hutchinson-Guilford's progeria, a sporadic disease affecting young children, and Werner's Syndrome, a heritable di sease affecting young adults (Salk et al. 1985). Werner's Syndrome is attributable to recessive, loss-of-function mutations in the WRN gene (Epstein et al. 1966; Goto et al. 1992). Werner's individuals di splay phenotypes including cataracts, hair loss and graying, loss of subcutaneous fat cells, aging of the skin, atherosclerosis, osteoporosis, diabetes, and cancer (Salk et al. 1985). Their average life span is 45 years. The WRN gene ( $Y u$ et al. 1996) is homol ogous to a group of DN A helicases, including recQ of Escherichia coli, SGS1 of S. cerevisiae (Gangl off et al . 1995), rqh1 of Schizosaccharomyces pombe (Stewart et al. 1997), and BLM, mutations of which cause Bloom's Syndrome (Ellis et al. 1995). The symptoms of Werner's and Bloom's Syndromes are quite different, suggesting that some aspect of specificity of the WRN helicase may lie at the core of the aging phenotypes (Lombard and Guarente 1996).

This paper will focus on one of the many promising new directions in the field of aging-a possible link between aging and changes in the nucleolus. This study is but one of many that use model systems to reveal molecular features of aging that may be rel evant to human aging.

\section{Two independent experimental paths to the nucleolus}

Redistribution of the Sir complex to the nucleolus

Mutations in two genes that extend yeast mother cell life span have been characterized. One gene, SIR4, encodes a protein that exists in a complex with Sir2p and Sir3p, which mediates transcriptional silencing at telomeres and HM loci (Rine and Herskowitz 1987; Gottschling et al. 1990; A paricio et al. 1991). Immunolocalization in yeast nuclei displays the Sir $2 / 3 / 4 p$ complex bound to telomeres in several perinuclear clusters (Pal ladino et al. 1993). In addition, Sir2p functions al one at the rDN A repeats to lower the rate of recombination in that tandem array (Gottlieb and Esposito 1989). Immunolocalization shows that Sir2p is present at both the rDN A and telomeres (Gotta et al. 1997).

The SIR4-42 mutation extends life span 50\% and

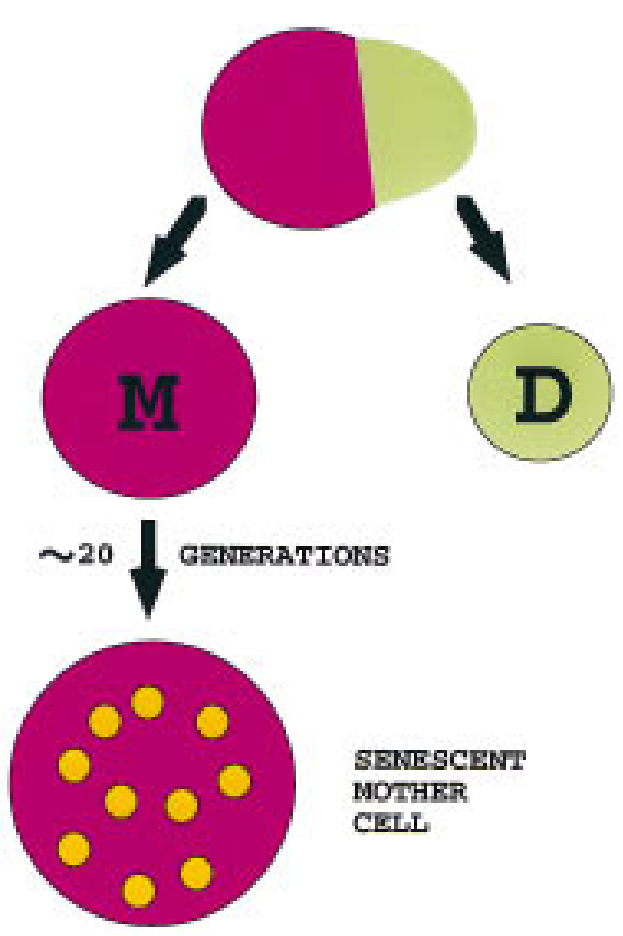

Figure 2. Aging in yeast mother cells. Budding yeast divide asymetrically giving rise to a large mother cell (M) and a smaller daughter cell (D). By microscopic manipulation, the same mother can be followed through repeated divisions, and after $\sim 20$ generations, cell division ceases and the senescent cells display phenotypes of aging. Shown here are cell enlargement and the accumulation of intracellular blebs of unknown composition. 
causes sterility due to loss of silencing of $\alpha$ and a mating genes at HML and HMR (Kennedy et al. 1995). A null mutation in SIR4 also causes sterility, but actually shortens life span (Table 1). Thus, SIR4-42 is a gain-offunction mutation for life-span extention. What function has this mutant gained? We initially argued on genetic grounds that the SIR4-42 mutation prevented recruitment of the Sir complex to telomeres and HM loci and freed the complex to go to a novel genomic site important in life span. Consistent with this view, the mutation truncated the protein to remove a carboxyl terminus that may anchor the wild-type Sir complex to telomeres and $\mathrm{HM}$ loci.

Subsequent immunolocalization revealed that the SI R4-42 complex no longer resided at telomeres but was relocalized to the nucleolus (Kennedy et al. 1997). The nucleolus is a region of the nucleus containing rRN A, proteins, and 120-200 tandem copies of rDN A on chromosome 12. It is the site of ribosome synthesis and assembly. This finding provided an initial clue that nucleolar changes might be important in aging.

A nother gene identified in the screen was UTH4 (Kennedy et al . 1995). The expression level of U TH4 dictates life span; null mutants have short life spans, and hyperexpression strains have unusually long life spans (Table 1) (Kennedy et al. 1997). A genetic link exists between UTH4 and SIR4. The SIR4-42 mutation is an allele-specific suppressor of a frameshift mutation in UTH4 that is a naturally occurring polymorphism in some yeast strains. UTH4 is homologous to two other genes in the yeast genome, YGL023 and YLL013, as well as to the Drosophila gene pumilio. UTH4 requires the integrity of the Sir complex to affect life span, indicating that it functions by regulating some aspect of the Sir complex. Indeed, the nucleolar localization of the SIR442 complex is abolished in strains mutant in both UTH4 and YGL023 (Kennedy et al. 1997). In another study, it was found that Sir3p goes to the nucleol us when SIR4 is deleted and that this nucleolar localization al so requires UTH4 (Gotta et al. 1997). Thus, our findings on SIR4-42 and UTH4 suggest the following model. Damage to the nucleolus might accumulate in mother cells to cause aging. This may be partially counteracted by the redistribution of the SIR4-42 complex to promote Iongevity.

What function might nucleolar localization of Sir

Table 1. Properties of SIR4 and UTH4 alleles

\begin{tabular}{lcll}
\hline & Sterility & $\begin{array}{l}\text { Location of } \\
\text { Sir complex }\end{array}$ & Life span \\
\hline Wild type & no & telomeres & medium \\
$\Delta$ sir4 & yes & none & short \\
SIR4-42 & yes & nucleolus & long \\
$\Delta$ uth4 & no & telomeres & short \\
$\uparrow$ UTH4 & no & telomeres & long
\end{tabular}

aThe extention of life span by SIR4-42 occurs in a strain with a partially defective al lel e of UTH4, i.e., SI R4-42 is a suppressor of this uth4 allele (Kennedy et al. 1997).
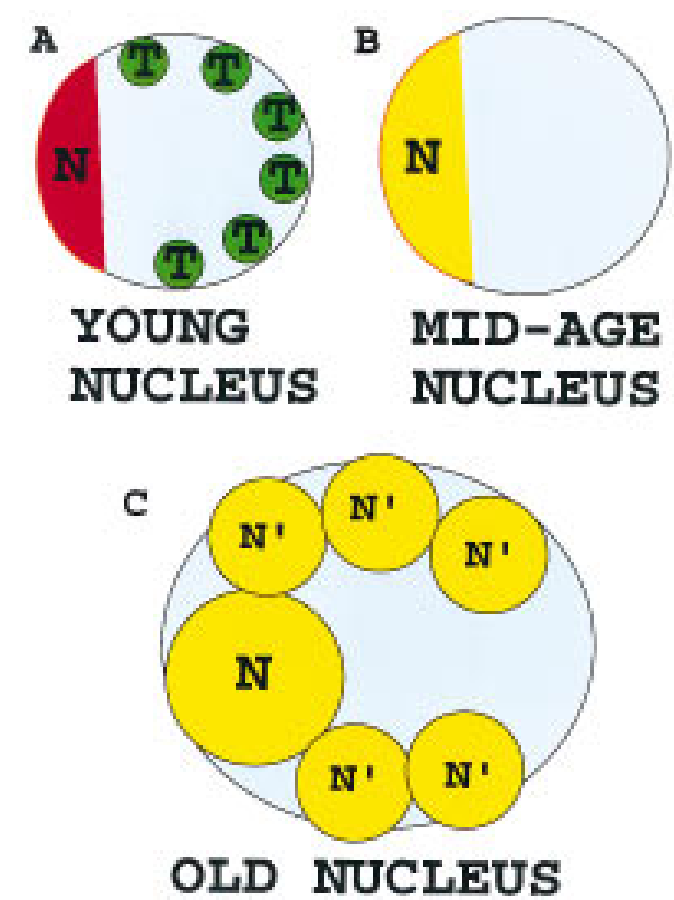

Figure 3. The localization of the Sir complex (as stained with anti-Sir3p) and the nucleolus (as stained with anti-Noplp) in mother cells of various ages. In nuclei of young cells (A), the Sir complex (green) is at the perimeter of the nucleus and is bound to bundles of telomeres $(T)$. The nucleolus ( $N$, red) is a discrete crescent at one side of the nucleus. After cells have completed one-half to two-thirds of their life spans and are now in middle age (B), the Sir complex has redistributed to the nucleolus (yellow in the merged image). In very old cells (C), the nucleolus enlarges and fragments into several nucleolar bodies $\left(\mathrm{N}^{\prime}\right)$ around the perimeter of the nucleolus. The Sir complex is found in all of these bodies.

complexes play in the life span of wild-type cells? We speculated that the SIR4-42 mutation mimicked and strengthened a response that normally occurred in wildtype old mother cells-redistribution of the Sir complex to the nucleol us to promote longevity. Strikingly, this turned out to be the case. When wild-type cells that had completed about two-thirds of their life span were isolated and immunostained, Sir3p was found to be redistributed from telomeres and $\mathrm{HM}$ loci to the nucleolus (Fig. 3A,B) (Kennedy et al. 1997). This finding explained our earl ier observation that old cells adopt the aging phenotype of sterility as a result of a loss of silencing at HM loci (Smeal et al. 1996). Thus, both aging-specific sterility and longevity appear to be attributable to the same molecular event-the redistribution of the Sir complex to the nucleolus.

\section{The yeast WRN homolog SGSI and life span}

Why do Werner's individuals show symptoms that phenocopy premature aging? It is likely that these symptoms arise at the cellular level because of one or more 
defects in chromosome biology (Guarente 1996). This view suggests that aging may be caused by defects that occur at the cellular level rather than a breakdown sol ely in some organismal (e.g., endocrinological or immunological) process. As one approach to identifying the cellular function of WRN, the study of WRN homologs in model systems offers promise. The yeast homolog SGS1 was identified because loss-of-function mutations suppress the slow growth in top3 (topoisomerase 3) mutants (Gangl off et al. 1994). Sgslp was shown to bind to topoisomerases 2 and 3 and to affect recombination (including at the rDN A loci) and chromosome segregation (Gangl off et al. 1994; Watt et al. 1995, 1996).

To determine whether SGS1 was involved in yeast life span, the gene was disrupted (Sinclair et al. 1997). Mutants were found to age prematurely by three criteria: (1) Their average life span was shortened by $60 \%$; (2) mother cells became sterile over their shortened life span as a result of loss of silencing at HM Ioci; and (3) the Sir complex redistributed to the nucleolus in old cells. Premature aging was specific to sgs 1 mutants because other randomly chosen yeast mutations either did not shorten life span, or, if they did, did not cause the appearance of sterility in aging mother cells.

Sgslp was immunolocalized to the nucleus, with a concentration in the nucleolus (Sinclair et al. 1997). This prompted an examination of the nucleoli in old sgs 1 mothers. Whereas in young sgsl or wild-type cells the nucleolus is a crescent-shaped structure at one side of the nucleus, strikingly, in old sgs 1 mother cells the nucleol us was enlarged and fragmented (Fig. 3C) (Sinclair et al. 1997). These changes caused the nucleolus to occupy at least $50 \%$ of the nucl ear volume in most cells. In cells with these fragmented nucleoli, the Sir complex redistributed to all of the nucleolar bodies. Significantly, similar changes were found in nucleoli of very old wildtype cells, indicating that they are not a consequence of the sgs 1 mutation per se. Thus, like the analysis of the Sir complex above, the study of SGS1 also suggests that nucleolar changes might be important in the aging of yeast mother cells.

Finally, the relationship between the fragmentation of the nucleol us and the redistribution of the Sir complex was examined. Assuming that the fragmentation of the nucleolus is relevant to aging, there are two extreme possibilities. The first is that the redistribution of the Sir complex de lays the fragmentation of the nucleolus and thus provides longevity. The second possibility is the redistribution of Sir proteins causes the fragmentation of the nucleolus, and these fragments do not cause aging but promote longevity. Two experiments suggest that the first possibility is correct (Sinclair et al. 1997). In one experiment, old cells were examined in a sir3 mutant, and the nucleoli were found to be fragmented. Thus, fragmentation does not require the Sir complex. In the second experiment, age-matched cells of 12 generations were obtained from wild-type and sir3 mutant strains, and fragmentation was found much more commonly in the sir3 mutant. This finding suggests that the Sir complex could function to delay fragmentation in wild-type cells.

\section{A model for aging in dividing cells-the nucleol us and telomeres}

The above findings begin to provide a model for aging that draws on the idea that cells undergo cumulative damage to chromosomes, most likely focused on the rDN A (Guarente 1996). The rDN A may be the Achilles' heel of the cell because it comprises a potentially unstable array of tandemly repeated DN A sequences. A loss of the ability to maintain this stability may lie at the heart of aging. Evolution may have selected for counteracting response mechanisms to forestall this damage and promote longevity, as exemplified by the redistribution of the Sir compl ex to the nucleol us in aging yeast mother cells. The life span of an organism is then the sum of the rate of accumulation of this damage and the robustness of the response mechanism (Guarente 1997).

Three key questions must be addressed in the near term regarding this mechanism of aging. First, what is the precise nature of the changes that occur in the yeast nucleolus, and how might these alterations cause aging of mother cells? Second, how does the redistribution of the Sir complex to the rDNA forestall these changes? Third, how general are these mechanisms in the aging of other organisms, particularly in mammals?

\section{A telomere-rDNA balancing act}

The functional role of Sir protein positioning at yeast telomeres has remained obscure. No telomeric yeast genes are known to be subject to silencing in wild-type strains. In contrast, silencing at the rDNA does occur and is mediated by Sir2p (Bryk et al. 1997; Smith and Boeke 1997). It has been proposed that telomeres might serve as a reservoir or sink for the silencing factors ( $M$ aillet et al . 1996; M arcand et al . 1996). Our findings suggest that these reserves of the Sir complex are released from telomeres as yeast cells age to provide longevity (Fig. 4). Indeed, if telomere length is manipulated to a new steady-state length by genetical ly al tering tel omerase or the tel omeric protein Raplp, we find that shortened telomeres increase life span and elongated telomeres decrease life span (Austriaco and Guarente 1997). We imagine that the shortened telomeres facilitate the redistribution of the Sir complex, whereas elongated telomeres have the opposite effect. However, because yeast telomeres do not normally shorten in aging mother cells (D'M ello and Jazwinski 1991; Smeal et al. 1996), we imagine that there must be some novel mechanism causing redistribution of the Sir complex. One possibility is that old cells signal a post-translational modification of one or more Sir proteins that prevents their recruitment to telomeres and HM loci and thus elicits redistribution to the rDN A (Fig. 4).

In human dividing somatic cells, telomeres do shorten with age because the soma lacks telomerase (Alsopp et al. 1992). We have suggested that this shortening may aid in the release of telomere-bound proteins to another chromosomal locus, perhaps the nucleolus, to promote Iongevity (A ustriaco and Guarente 1997; Kennedy et al. 


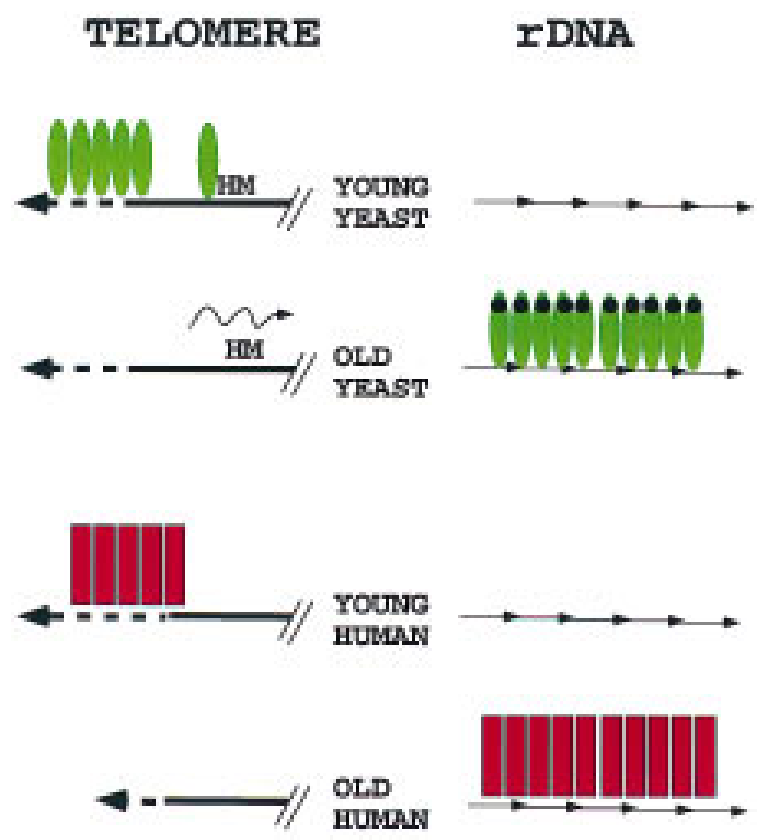

Figure 4. Model for redistribution of telomeric proteins to the rDNA (at the nucleolus) in yeast and humans. In young yeast cells, the Sir complex (green ovals) is located at tel omeres (broken line) and $\mathrm{HM}$ loci. In old cells, these proteins redistribute to the rDNA, perhaps because of some post-translational modification in a Sir protein (black dots). This redistribution causes a lengthening in life span, attributable to localization at the rDN A, and sterility, because of departure from HM loci. In humans, we hypothesize that tel omere-binding proteins (red rectangles) might also redistribute from telomeres to the rDNA in aging individuals because of telomere shortening. By anal ogy to yeast, this could promote longevity and elicit phenotypes of aging.

1997) (Fig. 4). It is al so likely that very long-lived animals lack telomerase (and thus undergo telomere shortening) as a safeguard against the unrestrained growth of tumor cells. In mice, which only live about 2-3 years, telomeres can be very long and shortening has not been observed in aging animals. It would be of interest to investigate whether telomere shortening occurs in other very longlived animals, such as Galapogos turtles.

\section{Aging in mammals-dividing vs. nondividing cells}

What does the information that has emerged from yeast and $C$. elegans tell us about human aging? It is possible that aging in humans will be divided into two mechanistic catagories that apply to organs with dividing cells versus postmitotic cells. In C. elegans, in which all of the adult cells are postmitotic, aging studies have pointed to the importance of metabolic rate and, perhaps, oxidative damage Johnson 1996; Ewbank et al. 1997). Thus, it is possible that aging in the mammalian brain and heart is elicited by oxidative damage that accumulates over time, perhaps provoking the gradual death of cells.
Aging in yeast mother cells provides a rather different picture, in which changes in the nucleolus appear to be paramount. The fact that mutation in the yeast SGS1 gene, a homolog of WRN, causes premature aging and nucleolar changes in yeast mother cells (Sinclair et al. 1997) suggests that phenocopies of premature aging can be elicited in both yeast and humans by the same mechanism. Werner's Syndrome has been termed a segmental aging disease because only some organs are affected (Salk et al . 1985). Interestingly, affected organs general ly consist of dividing cells, and at least one organ with postmitotic cells, the brain, is not affected in Werner's individuals. Thus, aging in dividing cells of normal mammals may be caused at least in part by a mechanism involving changes in the rDN A.

Finally, it has been noted that cultured human cells (fibroblasts) divide a rel atively fixed number of times and then senesce (Hayflick 1965). Interestingly, fibroblasts from a variety of different animals divide a number of times roughly proportional to the life span of the animal (Finch 1990). Thus, it has been proposed that in vitro senescence of primary fibrobasts is a model for aging. This view is buttressed by the fact that cells from Werner's individuals divide fewer times in culture (T ollefsbol et al. 1984; Salk et al. 1985). In addition, cellular markers of senescence have been reported in both senescent fibroblasts and el derly animals (Campisi 1996). Although aging in cultured cells is an attractive model, there are reasons to believe that fibroblast senescence may be mechanistically distinct from aging in the animal. One incongruity is that cells from the severe HutchinsonGuilford's progeroids divide more times in vitro than cells from Werner's individuals (Tollefsbol et al. 1984). Furthermore, fibroblasts from individuals with other nonaging-related di seases can display a reduced number of cell divisions in vitro (Weksberg et al. 1979). Thus, it remains to be demonstrated that there is a mechanistic relationship between in vitro senescence and aging.

\section{Perspective}

A pervasive view holds that aging is a many-faceted process that will not conform to any single mechanistic cause. A corollary of this view is that many cellular processes break down at roughly the same time because there has been no selection for any greater duration of maintenance. Studies in the model systems of yeast and C. el egans argue against this idea because mutations in single genes can exert substantial extensions in the life span of the organism. Thus, there may be a limited number of cellular events that figure most prominently in aging, perhaps including fragmentation of the nucleolus. Once the Achilles' heel(s) of the cell has been precisely identified, one can imagine interventions to slow changes that occur with aging. M eeting the chall enges of aging and its accompanying infirmities has been a primary undertaking of biomedical research in the twentieth century. A search for the causes of aging will continue this mission into the next century. The spirit of Ponce de Leon lives on! 


\section{References}

Allsopp, R.C., H. Vaziri, C. Patterson, S. Goldstein, E.V. Yunglai, A.B. Futcher, C.W. Greider, and C.B. Harley. 1992. Telomere lengths predicts replicative capacity of human fibroblasts. Proc. Natl. Acad. Sci. 89: 10114-10118.

Aparicio, O.M., B.L. Billington, and D.E. Gottschling. 1991. Modifiers of position effect are shared between telomeric and silent mating-type loci in S. cerevisiae. Cell 66: 12791287.

Austriaco, N.R. and L. Guarente. 1997. Changes of telemere length cause reciprocal changes in the life span of mother cells in S. cerevisiae. Proc. N at. Acad. Sci. 94: 9768-9772.

Bryk, M., M. Banerjee, M. Murphy, K.E. Knudsen, D.J. Garfinkle, and M.J. Curcio. 1997. Transcriptional silencing of Ty1 elements in the RDN 1 locus of yeast. Genes $\&$ Dev. 11: 255-269.

Campisi, J. 1996. Replicative senescence: An old lives' tal e? Cell 84: 497-500.

D'mello, N.P. and S.M. Jazwinski. 1991. Telomere length constancy during aging of Saccharomyces cerevisiae. J. Bacteriol. 173: 6709-6713.

D'mello, N .P., A.M. Childress, D.S. Franklin, S.P. Kale, C. Pinswasdi, and S.M. Jazwinski. 1994. Cloning and characterization of LAG1, a longevity-assurance gene in yeast. J. Biol. Chem. 269: 15451-15459.

Ellis, N .A., J. Groden, T. Ye, J. Straughen, D.J. Lennon, S. Ciocci, M. Proytcheva, and J. German. 1995. The Bloom's syndrome gene product is homologous to RecQ helicases. Cell 83: 655666.

Epstein, C.J., G.M. Martin, A.L. Schultz, and A.G. Motulsky. 1966. Werner's syndrome: A review of its symptamotology, natural history, pathologic features, genetics, and relationship to the natural aging process. Medicine 45: 177-221.

Ewbank, J.J., T.M. Barnes, B. Lakowski, M. Lussier, H. Bussey, and S. Hekimi. 1997. Structural and functional conservation of the Caenorhabditis elegans timing gene clk-1. Science 275: 980-983.

Finch, C.E. 1990. Longevity, senescence, and the genome. University of Chicago Press, Chicago, IL.

Friedman, D.B. and T.E. Johnson. 1988. A mutation in the age-1 gene in Caenorhabditis el egans lengthens life and reduces hermaphrodite fertility. Genetics 118: 75-86.

Gangl off, S., J.P. McDonald, C. Bendixen, L. Arthur, and R. Rothstein. 1994. The yeast type 1 topoisomerase Top3 interacts with Sgs1, a DNA helicase homolog: A potential eukaryotic reverse gyrase. Mol. Cell. Biol. 14: 8391-8398.

Gompertz, B. 1825. On the nature of the function expressive of the law of human mortality, and on the mode of determining the value of life contingencies. Phil. Trans. Roy. Soc. 115: 513-585.

Gotto, M., M. Rubenstein, J. Weber, K. Woods, and D. Drayna. 1992. Genetic linkage of Werner's syndrome to five markers on chromosome 8. Nature 355: 735-738.

Gotta, M., S. Strahl-Bolsinger, H. Renauld, T. Laroche, B.K. Kennedy, M. Grunstein, and S.M. Gasser. 1997. Localization of Sir2p: The nucleolus as a compartment for silent information regulators. EMBO J. 16: 3243-3255.

Gottlieb, S. and R.E. Esposito. 1989. A new role for a yeast transcriptional silencer gene, SIR2, in regulation of recombination in ribosomal DNA. Cell 56: 771-776.

Gottschling, D.E., O.M. A paricio, B.L. Billington, and V.A. Zakian. 1990. Position effect at S. cerevisiae tel omeres: Reversible repression of pol II transcription. Cell 63: 751-762.

Guarente, L. 1996. Do changes in chromosomes cause aging? Cell 86: 9-12.
-_- 1997. What makes us tick? Science 275: 943-944.

Hayflick, L. 1965. The limited in vitro lifetime of human dipIoid cell strains. Exp. Cell Res. 37: 614-636.

Johnson, T. 1996. Cellular aging and cell death (ed. N. Holbrook, G. Martin, and R. Lockshin), pp. 1-17. Wiley-Liss, N ew York, NY.

Kennedy, B.K., N.R. Austriaco, Jr., J. Zhang, and L. Guarente. 1995. Mutation in the silencing gene SIR 4 can delay aging in S. cerevisiae. Cell 80: 485-496.

Kennedy, B.K., M. Gotta, D.A. Sinclair, K. Mills, D.S. M cN abb, M. Murthy, S.M. Pak, T. Laroche, S.M. Gasser, and L. Guarente. 1997. Redistribution of silencing proteins from telomeres to the nucleolus is associated with extension of life span in S. cerevisiae. Cell 89: 381-391.

Kenyon, C., J. Chang, E. Gensch, A. Rudner, and R. Tabtiang. 1993. A C. elegans mutant that lives twice as long as wild type. Nature 366: 461-464.

Kimura, K.D., H.A. Tissenbaum, Y. Liu, and G. Ruvkun. 1997. daf-2, an insulin receptor-like gene that regulates Iongevity and diapause in Caenorhabditis el egans. Science 277: 942946.

Lakowski, B. and S. Hekimi. 1996. Determination of life-span in Caenorhabditis elegans by four clock genes. Science 272: 1010-1013.

Lombard, D.B. and L. Guarente. 1996. Cloning the gene for Werner's Syndrome, a disease with many symptoms of premature aging. Trends Genet. 12: 283-286.

M aillet, L., C. Boscheron, M. Gotta, S. M arcand, E. Gilson, and S.M. Gasser. 1996. Evidence for silencing compartments within the yeast nucleus: A role for telemore proximity and Sir protein concentration in silencer-mediated repression. Genes \& Dev. 210: 1796-1811.

Marcand, S., S.W. Buck, P. Moretti, E. Gilson, and D. Shore. 1996. Silencing of genes at nontelomeric sites in yeast is controlled by sequestration of silencing factors at telomeres by Rap1 protein. Genes \& Dev. 10: 1297-1309.

Morris, J.Z., H.A. Tissenbaum, and G. Ruvkin. 1996. A phosphatidylinositol-3-OH kinase family member regulating longevity and diapause in Caenorhabditis elegans. Nature 382: 536-539.

M ortimer, R.K. and J.R. Johnston. 1959. Life span of individual yeast cells. Nature 183: 1751-1752.

Palladino, F., T. Laroche, E. Gilson, A. Axelrod, L. Pillus, and S.M. Gasser. 1993. SIR3 and SIR4 proteins are required for the positioning and integrity of yeast telomeres. Cell 75: 543-555.

Pohley, H.-J. 1987. A formal mortality analysis for populations of unicellular organisms. Mech. Aging Dev. 38: 231-243.

Proft, M., P. Kotter, D. Hedges, N. Bojunga, and K.-D. Entian. 1995. CAT5, a new gene necessary for derepression of gluconeogenic enzymes in Saccharomyces cerevisiae. EMBO J. 14: 6116-6126.

Rine, J. and I. Herskowitz. 1987. Four genes responsible for a position effect on expression from HML and HMR in Saccharomyces cerevisiae. Genetics 116: 9-22.

Salk, D., Y. Fujiwara, and G.M. Martin, eds. 1985. Werner's Syndrome and human aging. Plenum Press, N ew York, NY.

Sinclair, D.A., K. Mills, and L. Guarente. 1997. Accelerate aging and nucleolar fragmentation in yeast Sgs1 mutant. Science 277: 1313-1316.

Smeal, T., J. Claus, B. Kennedy, F. Cole, and L. Guarente. 1996. Loss of transcriptional silencing causes sterility in old mother cells of S. cerevisiae. Cell 84: 633-642.

Smith, J.S. and J.D. Boeke. 1997. An unusual form of transcriptional silencing in yeast ribosomal DNA. Genes \& Dev. 11: $241-254$. 
Stewart, E., C.R. Chapman, F. Al-Khodairy, A.M. Carr, and T. Enoch. 1997. rqh1t, a fission yeast gene related to the Bloom's and Werner's syndrome genes, is required for reversible S phase arrest. EMBO J. 16: 2682-2692.

Sun, J., S.P. Kale, A.M. Childress, C. Pinswasdi, and S.M. Jazwinski. 1994. Divergent roles of RAS1 and RAS2 in yeast longevity. J. Biol. Chem. 269: 18638-18645.

Tollefsbol, T.O. and H.J. Cohen. 1984. Werner's Syndrome: An underdiagnosed disorder resembling premaure aging. Age 7: 75-88.

Watt, P.M., E.J. Louis, R.H. Borts, and I.D. Hickson. 1995. Sgsl: A eukaryotic homolog of E. coli RecQ that interacts with topoisomerase II in vivo and is required for faithful chromosome segregation. Cell 81: 253-260.

Watt, P.M., R.H. Hickson, R.H. Borts, and E.J. Louis. 1996. SGS1, a homologue of the Bloom's and Werner's Syndrome genes, is required for maintenance of genome stability in Saccharomyces cerevisiae. Genetics 144: 935-945.

Weksberg, R., M. Buchwald, P. Sargent, M. Thompson, and L. Siminovitch. 1979. Cellular defects in patients with fanconi anemia. J. Cell Physiol. 101: 311-324.

Wong, A., P. Boutis, and S. Hekimi. 1995. Mutations in the clk-1 gene of Caenorhabditis el egans affect developmental and behavioral timing. Genetics 139: 1247-1259.

Yu, C.-E., J. Oshima, Y.-H. Fu, E.M. Wijsman, F. Hisama, R. Alisch, S. Matthews, J. N akura, T. Miki, S. Ouais, G.M. Martin, J. Mulligan, and G.D. Schellenberg. 1996. Positional cloning of the Werner's syndrome gene. Science 272: 258262. 


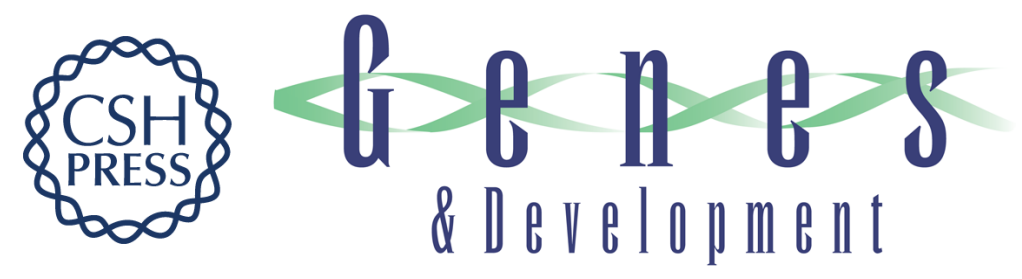

\section{Link between aging and the nucleolus}

\section{Leonard Guarente}

Genes Dev. 1997, 11:

Access the most recent version at doi:10.1101/gad.11.19.2449

References This article cites 43 articles, 21 of which can be accessed free at: http://genesdev.cshlp.org/content/11/19/2449.full.html\#ref-list-1

\section{License} Email Alerting
Service $\begin{aligned} & \text { Receive free email alerts when new articles cite this article - sign up in the box at the top } \\ & \text { right corner of the article or click here. }\end{aligned}$

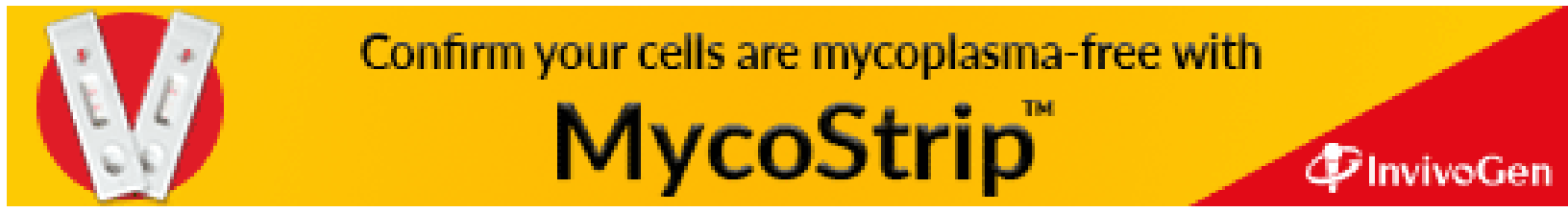

